\title{
Perspectivas plurais para a presença negra na Universidade Federal de Viçosa
}

\author{
Edimara Maria Ferreira ${ }^{1}$ \\ Tatiani Gomes Gouvêa ${ }^{2}$ \\ Universidade Federal de Viçosa
}

Resumo: Este artigo objetiva analisar a presença negra na Universidade Federal de Viçosa (UFV), campus Viçosa, através do levantamento do número de indivíduos pertencentes a este grupo e de suas marcas nos diversos espaços. Trata-se de uma pesquisa com enfoque quali-quantitativo, caracterizada como um estudo de caso, complementado pela pesquisa bibliográfica-documental e utilizando os dados de autoclassificação racial disponibilizados pela instituição e entrevistas com 25 servidores da mesma. Observou-se a prevalência de autodeclarados brancos no quadro funcional da instituição e que esta caminha para a equiparação entre brancos e negros em seu quadro estudantil.

Palavras-chave: Presença negra; Representação; UFV; Negros.

${ }^{1}$ Mestrado Profissional em Patrimônio Cultural, Paisagens e Cidadania, pela Universidade Federal de Viçosa (2017). Possui especialização em Gestão Pública pelas Faculdades Integradas de Jacarepaguá - FIJ (2012). Bacharel em Ciência e Tecnologia de Laticínios pela Universidade Federal de Viçosa (2009). Licenciada em Formação Pedagógica de Docentes Biologia pela Universidade de Franca (2012).

${ }^{2}$ Mestrado Profissional em Patrimônio Cultural, Paisagens e Cidadania, pela Universidade Federal de Viçosa (2017). Possui especialização em Psicopedagogia pela Empresa Viçosense de Assessoria Técnico-Acadêmica Ltda - EVATA (2006). Graduada em Pedagogia pela Universidade Federal de Viçosa (2004). 


\title{
Plural perspectives to the black people presence in the Federal University of Viçosa
}

\begin{abstract}
This article aims to analyze the black presence at Universidade Federal de Viçosa (UFV), Viçosa campus, by surveying the number of individuals belonging to this group and their marks in the various spaces. This is of a survey with a qualitative-quantitative focus, characterized as a case study, complemented by bibliographical-documental survey and using self-classified racial data provided by the institution and interviews with 25 servers of the same. It was observed the prevalence of self-declared white people on the institution functional picture and that this walks for the equivalence between whites and blacks people on its student body.
\end{abstract}

Keywords: Black presence; Representation; UFV; Blacks.

\section{Perspectivas plurales para la presencia negra en la Universidade Federal de Viçosa}

\begin{abstract}
Resumen: Este artículo objetiva analizar la presencia de los negros en la Universidade Federal de Viçosa (UFV), campus Viçosa, a través del levantamiento del número de individuos pertenecientes a este grupo y de sus marcas en los diversos espacios. Se trata de una investigación con enfoque cuali-cuantitativo, caracterizada como un estudio de caso, complementado por la investigación bibliográficadocumental y utilizando los datos de autoclasificación racial disponibilizados por la institución y entrevistas con 25 servidores de la misma. Se observó la prevalencia de autodeclarados blancos en el cuadro funcional de la institución y que esta camina para la equiparación entre blancos y negros en su cuadro estudiantil.
\end{abstract}

Palabras clave: Presencia negra; Representación; UFV; Negros. 


\section{Introdução}

s políticas públicas elaboradas pelo governo federal brasileiro, especialmente as de caráter social e que promovem a inclusão racial, são resultado de demandas de entidades e movimentos que trabalham em defesa da causa negra, tendo em vista que romper com a barreira da desigualdade e do preconceito faz parte das lutas e conquistas da população negra no Brasil, um país pluriétnico, mas desigual.

No entanto, apesar das grandes variações étnicas, persiste no país, ainda que algumas vezes de modo sutil, a prática da discriminação sócio-racial, do preconceito e do racismo, resultando em desigualdades de oportunidades que se manifestam em diversos espaços da sociedade brasileira, a exemplo do acesso à educação ou ao mercado de trabalho. À vista disso, a inserção social, efetivada através de políticas públicas, torna-se relevante para possibilitar a inclusão dos indivíduos aos meios sociais e garantir a equidade de acesso a direitos básicos a todos.

A adoção dessas medidas têm contribuído para a valorização da população negra e para o aumento do número de brasileiros e brasileiras que se autodeclaram pardos e pretos. É importante destacar que a utilização da terminologia parda remete ao período colonial, sendo utilizada para nominar alguns escravos de cor mais clara e, posteriormente, ampliou-se sua significação para designar os descendentes de africanos nascidos livres, já que os termos 'crioulo' e 'preto', utilizados à época, remetiam à condição social de escravo ou exescravo (MATTOS, 2004: 17).

Não obstante, apesar dessa crescente valorização, ainda é possível perceber a sub-representação das ditas 'minorias sociais' ou grupos 'racializados', especificamente os negros, em diversos espaços, como aponta a pesquisa realizada em uma instituição pública do Rio de Janeiro (RJ) que, embora o objetivo principal tenha sido determinar as estratégias individuais dos negros ${ }^{3}$ para ascender socialmente, evidenciou uma maior presença de estudantes negros em cursos como Ciências Sociais, Pedagogia e Serviço Social, considerados de baixos prestígio social e grau de competição (TEIXEIRA, 2003: 240-241).

Outrossim, uma pesquisa na Universidade Federal de Minas Gerais (UFMG) revelou a baixa representação de negros e negras em cargos de docentes (PRAXEDES et al., 2009 apud GONZAGA, 2011: 176). Além disso, pesquisa realizada com os técnicos-administrativos da mesma instituição revelou uma "invisibilidade ativamente produzida" entre estes sujeitos, sendo esta situação mais acentuada entre os autodeclarados negros (GONZAGA, 2011: 22). Corroborando com estas conclusões, estudo realizado sobre o servidor negro da Universidade Federal de Viçosa (UFV), apontou que 67\% dos servidores da instituição pertenciam à categoria branca e somente $21 \%$ à negra, o que demonstra a necessidade de garantir a inserção do negro no espaço universitário (BRAGA, 2014: 45).

Portanto, percebe-se que para entender a questão racial e combater as desigualdades e o preconceito raciais no país é necessário que estudos a respeito desta temática sejam desenvolvidos nos vários setores da sociedade, principalmente, em instituições educacionais às quais compete a formação do cidadão brasileiro.

3 Destaca-se, para efeito deste parágrafo, designamos como negros o conjunto formado pelas categorias utilizadas pela autora para denominar os indivíduos não brancos, a saber: pardos, mulatos e negros. 
Diante do exposto e considerando a institucionalização da reserva de vaga a negros em instituições públicas federais, o presente artigo objetiva analisar a presença negra na UFV, campus Viçosa, através do levantamento do número de estudantes e servidores (técnicos-administrativos e docentes) da instituição pertencentes a este grupo e de suas marcas em seus diversos espaços.

A escolha da UFV enquanto local para realização do estudo deve-se aos dados apresentados pela pesquisa científica, em nível de graduação, intitulada "A territorialidade do servidor negro da Universidade Federal de Viçosa”, desenvolvida por Braga (2014), que possibilitou vislumbrar um novo "olhar" sobre a presença negra na instituição. A experiência enquanto entrevistada permitiu que sentisse o quanto a questão racial ainda precisa ser discutida nos espaços universitários, da necessidade de garantir a inserção de negros e negras nestes espaços, bem como, reconhecer a sua importância na construção da identidade cultural do país. Para mais, pelos dados apresentados, percebeu-se que a UFV, apesar das políticas de inclusão, ainda não é efetivamente um espaço de inclusão (BRAGA, 2014: 45).

Sublinha-se que a análise da representatividade dos negros na educação superior e nos cargos e empregos da Administração Pública Federal faz-se necessária a fim de oferecer dados ao governo federal capazes de subsidiar o monitoramento de ações implementadas, a exemplo das políticas públicas inclusivas para esta população.

\section{Políticas públicas inclusivas para negros}

No âmbito das políticas para promoção da igualdade racial, diversas medidas e leis foram criadas desde 1946, a fim de promover a equidade racial, dentre as quais citamos:

- $\quad$ Constituição Federal de 1946, primeira legislação brasileira que indiretamente tratava da discriminação, pois nos $1^{\circ}$ e $5^{\circ}$ parágrafos do artigo 141 previa a igualdade de todos perante a lei e a proibição de propagandas preconceituosas de cunho de classes ou racial;

- $\quad$ Lei Afonso Arinos (Lei n. ${ }^{\circ} 1.390$, de o3 de julho de 1951), primeira lei antidiscriminatória do país, que considerava os atos de discriminação uma contravenção penal;

- Constituição Federal de 1988 que, no artigo $5^{\circ}$ (inciso XLII) prevê o racismo como crime inafiançável e imprescritível, no 68 legitima o direito de propriedade definitiva de suas terras aos descendentes quilombolas e no 216 (incisos I ao V e parágrafo $5^{\circ}$ ) reconhece a diversidade cultural e patrimonial do Brasil;

- Lei Caò (Lei n. ${ }^{\circ}$ 7.716, de o5 de janeiro de 1989) que modificou a Lei Afonso Arinos e trouxe a definição dos crimes resultantes de cor ou raça em sua redação, bem como, as penalidades resultantes destes;

- $\quad$ Programa Brasil Gênero e Raça, criado em 1998, com o objetivo de eliminar a discriminação no trabalho por meio da criação de Núcleos de Promoção da Igualdade de Oportunidades de Combate à Discriminação (FERREIRA E SANTOS, 200O:22);

- $\quad$ Decreto n. ${ }^{\circ}$ 4.228, de 13 de maio de 2002, que instituiu o Programa Nacional de Ações Afirmativas (PNAA), no âmbito da Administração Pública Federal, tendo com um de seus objetivos desenvolver mecanismos para garantir a 
ocupação de cargos comissionados por negros, mulheres e portadores de deficiência.

Cabe salientar que, ainda que algumas das leis e/ou medidas públicas apresentadas não terem alcançado o propósito institucional para o qual foram criadas, estas corroboraram para um cenário profícuo a fim de que avanços significativos fossem alcançados no campo educacional, sendo que, dentre estas conquistas, citamos:

- Lei.$^{\circ} 10.639$, de o9 de janeiro de 2003, que incluiu no currículo oficial da Rede de Ensino a obrigatoriedade do estudo da História da África e Cultura Afro-Brasileira;

- Lei.$^{\circ} 12.288$, de 20 de julho de 2010, que institui o Estatuto da Igualdade Racial, com o objetivo de garantir a igualdade de oportunidades, combate a todas as formas de discriminação étnico-racial e defesa dos direitos fundamentais mediante a implementação de políticas públicas voltadas para as áreas da saúde, educação, trabalho, cultura, esporte, lazer, dentre outras;

- $\quad$ Lei.$^{\circ} 12.711$, de 29 de agosto de 2012, que dispõe sobre a reserva de vagas nas universidades federais e nas instituições federais de ensino técnico de nível médio; $e$,

- Lei.$^{\circ} 12.990$, de o9 de junho de 2014, que reserva aos negros $20 \%$ das vagas oferecidas nos concursos públicos para cargos efetivos e empregos públicos no âmbito da Administração Pública Federal, autarquias, fundações públicas, empresas públicas e sociedades de economia mista controladas pela União.

Destaca-se que nosso intuito com o detalhamento da trajetória de conquistas em prol da igualdade racial, especialmente no campo educacional, foi demonstrar que o avanço das discussões, bem como as medidas tomadas para que tal propósito fosse alcançado, foram respostas à necessidade de promover a equidade racial e garantir a erradicação do racismo e inserção do negro nos diversos setores da sociedade. E, nesta premissa, o ápice de tais conquistas foi a promulgação da Lei n. ${ }^{0} 12.711 / 2012$ e da Lei n. ${ }^{\circ} 12.990 / 2014$.

Todavia, as Leis de Cotas (Lei n. ${ }^{0} 12.711 / 2012$ e Lei n. ${ }^{0} 12.990 / 2014$ ) e, até, o Estatuto da Igualdade Racial (Lei $n .{ }^{\circ} 12.288 / 2010$ ) dividiram opiniões de acadêmicos, intelectuais, ativistas dos movimentos sociais, dentre outros. Os defensores dessas leis têm por argumento o reconhecimento do preconceito e da discriminação racial enquanto condicionantes das desigualdades sociais no Brasil, sendo que, para estes, o problema racial no país vai além de umas simples questão econômica, mas resulta das condições díspares de acesso aos vários serviços desinentes do racismo cultivado ao longo da história desta sociedade (JACCOUD, 2009: 63).

Ao passo que, os contrários argumentam que a oportunidade de ascensão socioeconômica é menor para segmentos economicamente vulneráveis do que para os pertencem à determinada categoria racial, logo, as políticas públicas deveriam objetivar a eliminação da pobreza (JACCOUD, 2009: 62-63). Contudo, as cotas raciais funcionariam, mesmo que indiretamente, como uma forma de cota social, tendo em vista serem os negros uma das parcelas da sociedade em maior vulnerabilidade socioeconômica (GODOY, 2013: 24).

É interessante notar que há ainda quem defenda a aplicação das cotas para o ingresso no ensino superior, mas que é contrário a estas quando utilizadas em concursos público, ou seja, que considera o sistema de cotas para o ensino superior constitucional, enquanto que para ingresso em cargos e empregos públicos como inconstitucional, tendo vários motivos para tal inconstitucionalidade, 
como, por exemplo, o princípio da meritocracia e igualdade de condições (LIMA, 2016: 286 e 312).

A este respeito, cabe destacar que, apesar do modo de ingresso nos cargos públicos pressupor critérios neutros, o percurso educacional dos candidatos são diferentes, isto é, parte-se da tese que a condição socioeconômica dos negros impossibilita o adequado tempo de estudo para preparação para os concursos, além do acesso a escolas de nível fundamental e médio com melhor qualidade de ensino e a cursos preparativos, o que possibilitaria a concorrência em igualdade de condições para todos os candidatos (SILVA E SILVA, 2014: 5).

Não obstante, o grande argumento para aqueles que se dizem contrários às políticas de ações afirmativas raciais é a impossibilidade de definição clara de quem serão os beneficiários destas. No tocante a isto, ainda que não exista biologicamente a definição de raça humana, apesar de historicamente esta ter sido condicionante de exclusões, discriminações e desigualdades sociais, tal premissa não se aplicaria ao Brasil, devido à formação de uma nação multiétnica, o que impossibilitaria definir quem é negro baseando-se na classificação racial do IBGE e, consequentemente, a aplicação do sistema de cotas (LIMA, 2016: 287-288).

Deste modo, na aplicação de políticas compensatórias, devido à dificuldade para definição de quem é negro no país, restariam duas alternativas: regularizar e definir as raças existentes no Brasil ou a autoclassificação, tendo o país elegido a adoção da última (REZENDE, 1998-2007: 9). Entretanto, tal crença de impossibilidade de definir quem é negro foi aos poucos se desfazendo (HERINGER, 2002: 55), sendo que os brasileiros não demonstram nenhuma dificuldade para autoidentificar-se, nas pesquisas domiciliares do IBGE, através das cinco categorias raciais do Instituto (SANTOS, 2003: 86), o que em tese validaria sua utilização.

Diante do exposto, apresentamos no tópico subsequente um breve relato sobre a evolução das categorias e sistemas de classificação raciais, a fim de fundamentar a utilização da autoclassificação enquanto método classificatório e das categorias de cor/raça do IBGE na implementação das políticas de ação afirmativa.

\section{Métodos e categorias de classificação raciais}

Os métodos de classificação racial são, basicamente três: a autoclassificação que é a informação de pertença racial dada pelo próprio indivíduo, a heteroclassificação que é a classificação racial realizada por terceiros e a análise genética que é a classificação racial com base na quantidade de genes (OSORIO, 2013). O autor destaca que o método da análise genética é controverso, tendo em vista que a raça é uma construção sociológica e que o racismo brasileiro baseia-se em aparência física, a exemplo da cor de pele, portanto, os atos de discriminação apoiamse em características fenotípicas e não no material genético.

No que se refere à auto e heteroclassificação, salienta-se que, nas pesquisas domiciliares, indiretamente, o IBGE utiliza os dois métodos, tendo em vista que na ausência de algum dos moradores ou diante da impossibilidade destes se autoclassificarem, uma mesma pessoa realiza a identificação racial destes, sendo esta heteroidentificação realizada por pessoas próximas ao indivíduo classificado, o que subentende-se que a classificação seria semelhante à autoatribuída (OSORIO, 2013). 
Quanto às categorias, conforme recomendação dos organismos internacionais, o IBGE utiliza o método de autoclassificação racial, atualmente, tendo por base cinco categorias: branca, preta, parda, amarela e indígena. A principal crítica a essas categorias é que estas não contemplam a riqueza de termos utilizados pelos brasileiros para definir sua pertença racial (OSORIO, 2013).

A este respeito, sublinha-se que, em 1976, em um de seus levantamentos, o IBGE acrescentou uma pergunta aberta a fim de determinar em que proporção as caterigorias censitárias diferiam dos termos usados no cotidiano, sendo que apesar da quantidade de terminologia apresentada, 57\% destas se enquadrariam nas categorias do Censo, ou seja, "mesmo que as categorias censitárias limitem a riqueza de termos raciais usados pela população e eliminem seu caráter ambíguo, elas estariam conseguindo expressar o modo como a maior parte dos brasileiros se percebe racialmente" (QUEIROZ, 2002: 3).

Destaca-se que, desde o Censo Demográfico de 1872, categorias diversas foram utilizadas pelo IBGE para classificação racial dos brasileiros: em 1872 foram utilizadas as categorias branca, preta, parda e cabocla; em 1890 utilizou-se as categorias anteriores com o termo mestiço em substituição ao pardo; em 1940 utilizou-se apenas as categorias branca, preta e amarela, sendo as demais respostas, posteriormente, classificadas como categoria parda; de 1950 a 1980 utilizou-se a categorização branca, preta, parda e amarela; e, a partir de 1991, além das categorias anteriores, incluiu-se a indígena (IBGE, 2011).

Cabe salientar que o sistema classificatório brasileiro diferencia as categorias raciais de acordo com a variável cor de pele, uma vez que, historicamente, o preconceito brasileiro baseia-se em características fenotípicas, principalmente, cor de pele.

Sublinha-se que neste estudo utilizou-se as categorias raciais do IBGE, sendo a categoria genérica negros o somatório de pardos e pretos. É importante destacar que a agregação de pardos e pretos em um mesmo grupo justifica-se tendo em vista as similitudes das condições socioeconômicas e pela natureza similar das possíveis e reais discriminações sofridas pelos dois grupos (OSORIO, 2003: 24). Isto posto, apresentamos no tópico seguinte os resultados da autoclassificação racial dos servidores e estudantes da UFV, disponibilizados pela PróReitoria de Gestão de Pessoas (PGP) e pela Diretoria de Registro Escolar (RES).

Cumpre-se notar que a UFV situa-se na Zona da Mata Mineira, na cidade de Viçosa/MG, que, segundo o Censo Demográfico 2010 do IBGE, possui 72.220 habitantes, dos quais 37.924 são negros (agrupando as categorias preta e parda).

Outrossim, a cafeicultura exerceu um papel primordial no povoamento desta região, possibilitando o surgimento de fazendas, povoados e vilas (VALVERDE, 1958 apud HONÓRIO, 2012), sendo que, de acordo com a Lista Nominativa de Habitantes de 1831, o povoado era habitado por uma maioria parda e crioula, que correspondiam a $62 \%$ da população, dos quais $30 \%$ eram escravizados4 (COSTA, 2013: 32), ou seja, já em seus primórdios a cidade era habitada por uma maioria negra.

Assim, uma vez que a UFV situa-se em uma região que teve grande quantidade de negros escravizados e que continua composta, predominantemente, por negros, este estudo objetivou verificar se tal realidade manifesta-se entre os estudantes e servidores da instituição, isto é, se os negros se encontram representados, de modo significativo ou não, na UFV.

4 O termo escravo remete à ideia de uma condição consentida e imutável de "ser escravo", enquanto que escravizado dá a noção de um estado imposto e, possivelmente, transiente, ou seja, ser escravo diferente de estar escravizado (HARKOTDE-LA-TAILLE E SANTOS, 2012). 
Diante do exposto e tendo em vista a institucionalização da Lei $n .^{0}$ 12.711/2012 e da Lei 12.990/2014, o presente artigo teve por objetivo levantar o perfil racial dos servidores e estudantes de graduação da UFV, campus Viçosa, sendo o recorte temporal os anos de 2011 a 2015, a fim de analisar os dados dos primeiros anos de vigência das referidas leis. Além disso, haja vista o entendimento de que a presença negra não se resume a informações numéricas, mas contempla também a forma com essa presença se manifesta nos diversos espaços, buscou-se recuperar as marcas simbólicas ou iconográficas do negro encontradas na instituição.

Portanto, buscamos responder aos seguintes questionamentos: qual a população negra na Universidade Federal de Viçosa? Quais os vestígios e relações deste grupo dentro da instituição? Existem invisibilidades deste grupo na mesma?

\section{As múltiplas perspectivas para análise da presença negra na UFV}

Para responder os questionamentos anteriores fez-se necessário quantificar os indivíduos pertencentes a este grupo social dentro da instituição, o que se deu através da análise dos dados secundários extraídos da base de dados do Sistema de Gestão de Acesso (SIGAC) do Ministério do Planejamento e do Sistema de Apoio ao Ensino (SAPIENS), disponibilizados, respectivamente, pela PGP $^{5}$ e pela RES $^{6}$, órgãos da UFV, sendo o recorte temporal entre os anos de 2013 a 2015 para os servidores e 2000 a 2015 para os estudantes. Assim, considerando nosso recorte temporal, foram totalizados 476 servidores e 14.671 estudantes.

No que concerne ao perfil racial dos servidores (técnicos-administrativos e docentes) admitidos nas instituição entre os anos de 2013 e 2015, de acordo com o Gráfico 1, observou-se que 71,01\% se autodeclararam brancos e 28,99\% negros, sendo que, dentre os autodeclarados negros, 20,80\% eram pardos e 8,19\% pretos.

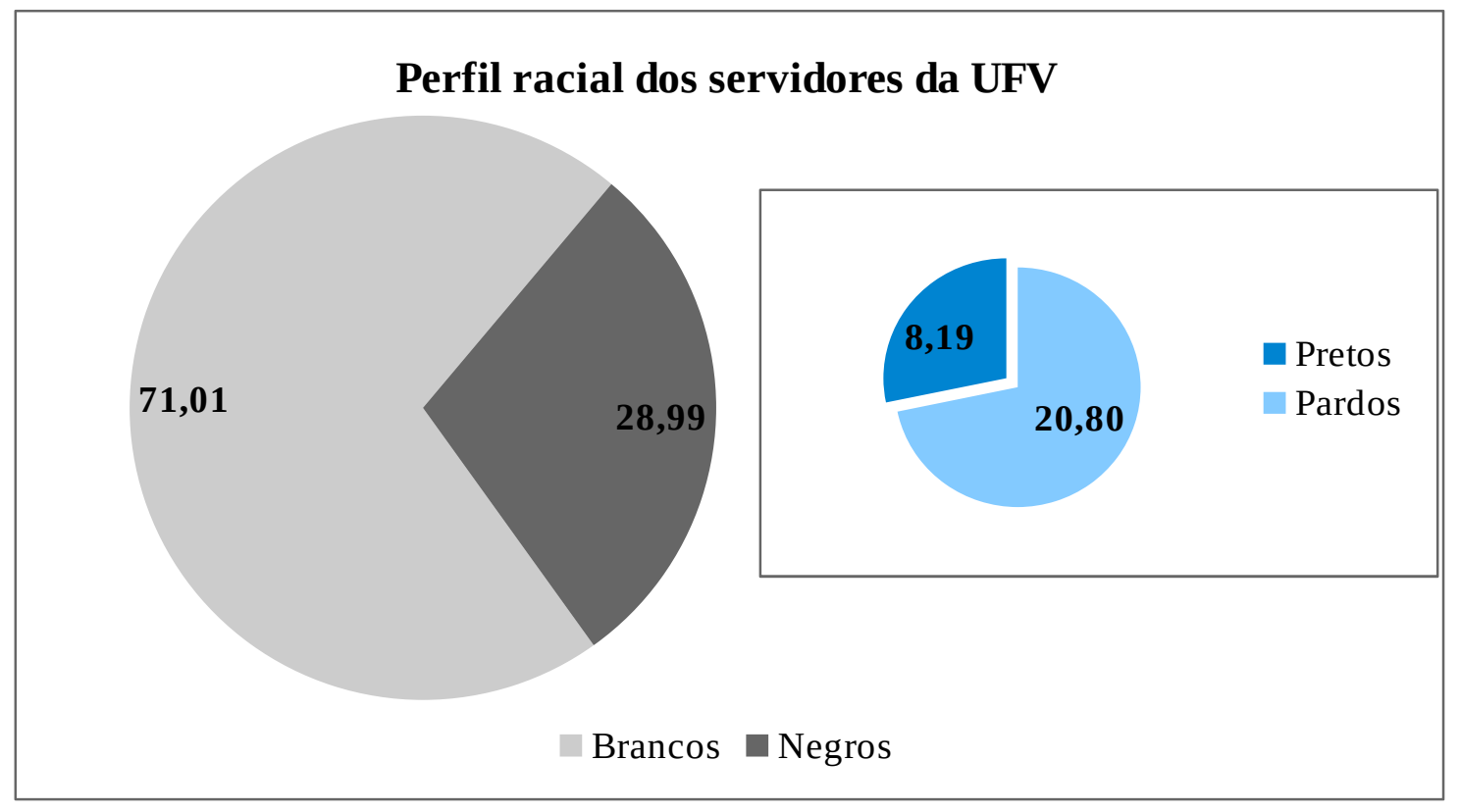


Salienta-se que, como apontado no Gráfico 2, verificou-se um aumento no quantitativo de servidores negros entre os anos de 2013 e 2014, registrando-se 28,57\% de negros em 2013 e 30,05\% em 2014 e em 2015 observou-se um decréscimo no quantitativo de servidores negros admitidos, apresentando $27,78 \%$ de negros neste último ano. Portanto, no período analisado houve uma taxa média de crescimento negativo de $15,66 \%$ no quantitativo negro. Ressalta-se ainda que o percentual de servidores brancos permaneceu superior ao de negros nos 3 anos analisados.

Cabe destacar que a Lei n. ${ }^{0} 12.990 / 2014$, que regulamenta a reserva de vagas para negros nos cargos e empregos públicos no âmbito da Administração Pública Federal, foi promulgada em o9 de junho de 2014.

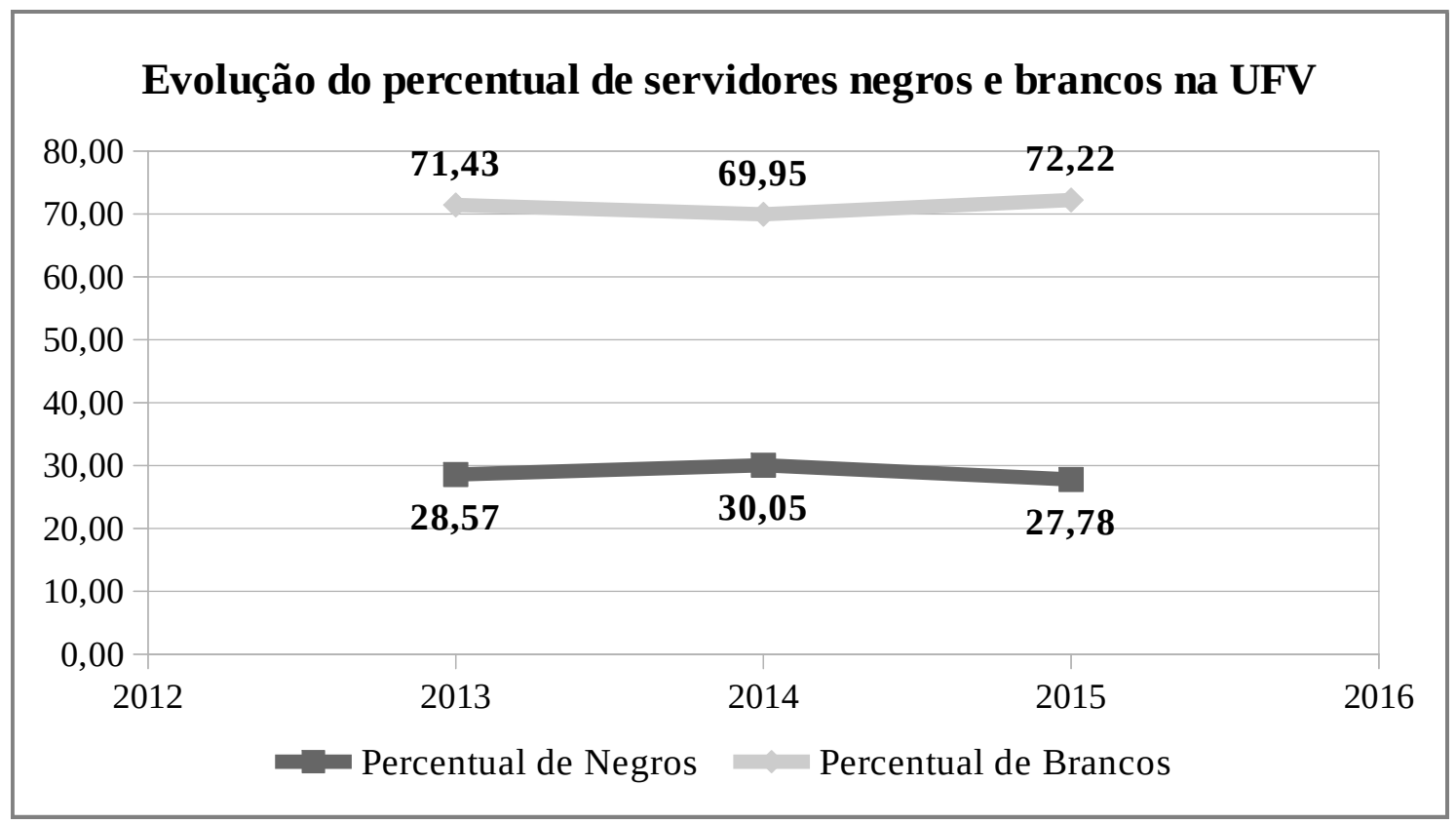

Gráfico 2: Evolução do percentual de servidores (técnico-administrativos e docentes) brancos e negros na Universidade Federal de Viçosa - admitidos entre os anos de 2013 e 2015. Fonte: Registro de dados da PGP. Elaborado pela autora.

Quanto à composição racial dos estudantes de graduação, de acordo com o Gráfico 3, constatou-se que 55,46\% dos graduandos se autodeclararam brancos, $41,68 \%$ negros (31,78\% pardos e 9,90\% pretos), 2,22\% amarelos e $0,63 \%$ como indígenas.

Cabe destacar que conforme Gráfico 4, houve um acréscimo gradativo no percentual de estudantes negros a partir do ano 2013, quando a instituição utilizou pela primeira vez o sistema de cotas, com registro de 43,24\% de negros em 2013, 44,20\% em 2014 e 45,21\% em 2015, o que corresponde a uma taxa média de crescimento de 0,10\% entre os anos de 2013 a 2015. Destaca-se que, pelos dados apresentados, a UFV caminha para a equidade no quantitativo de estudantes negros e brancos em seus cursos de graduação. 


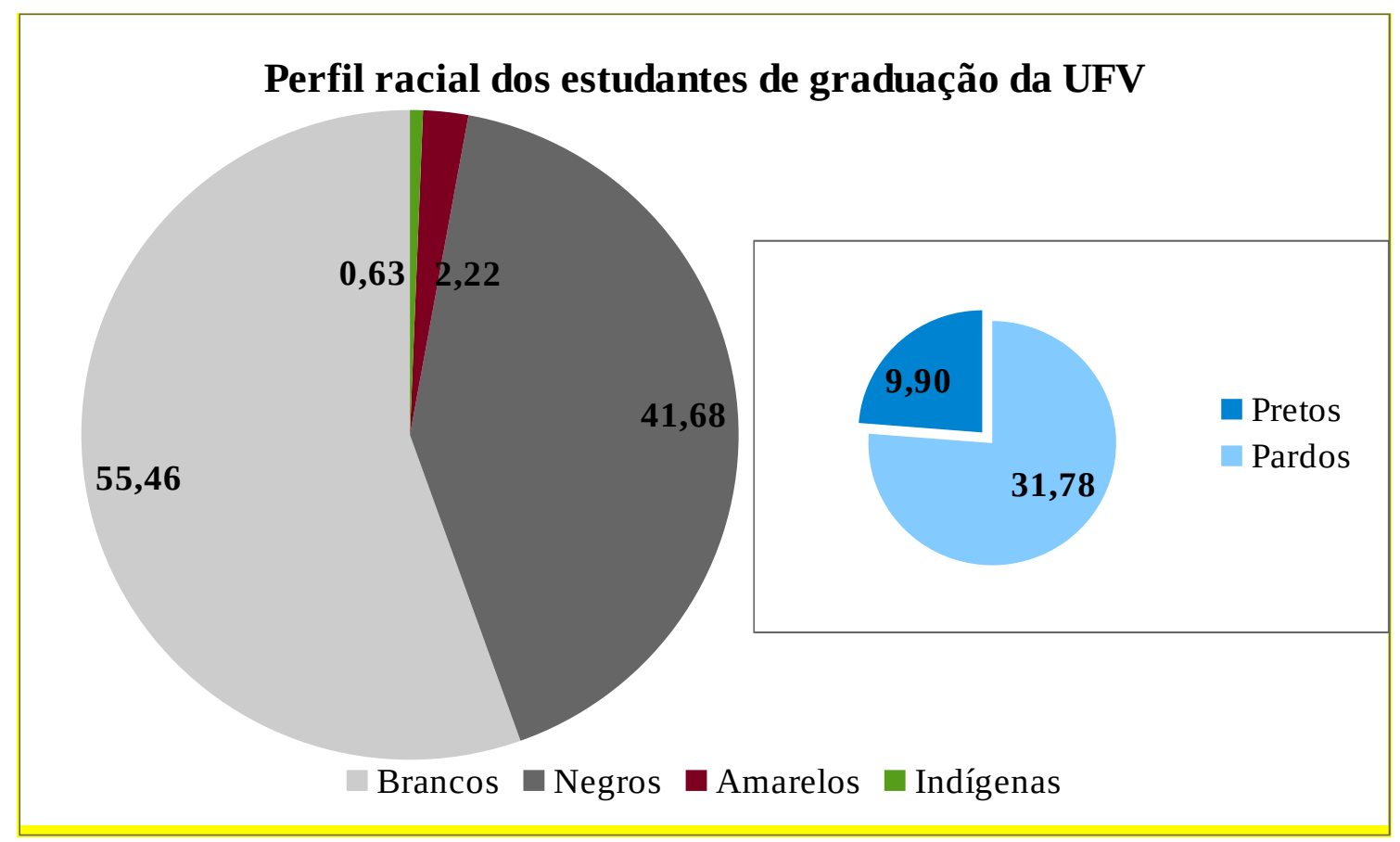

Gráfico 3: Composição racial dos estudantes de graduação da Universidade Federal de Viçosa - 2011 a 2015. Fonte: Registro de dados da RES. Elaborado pela autora.

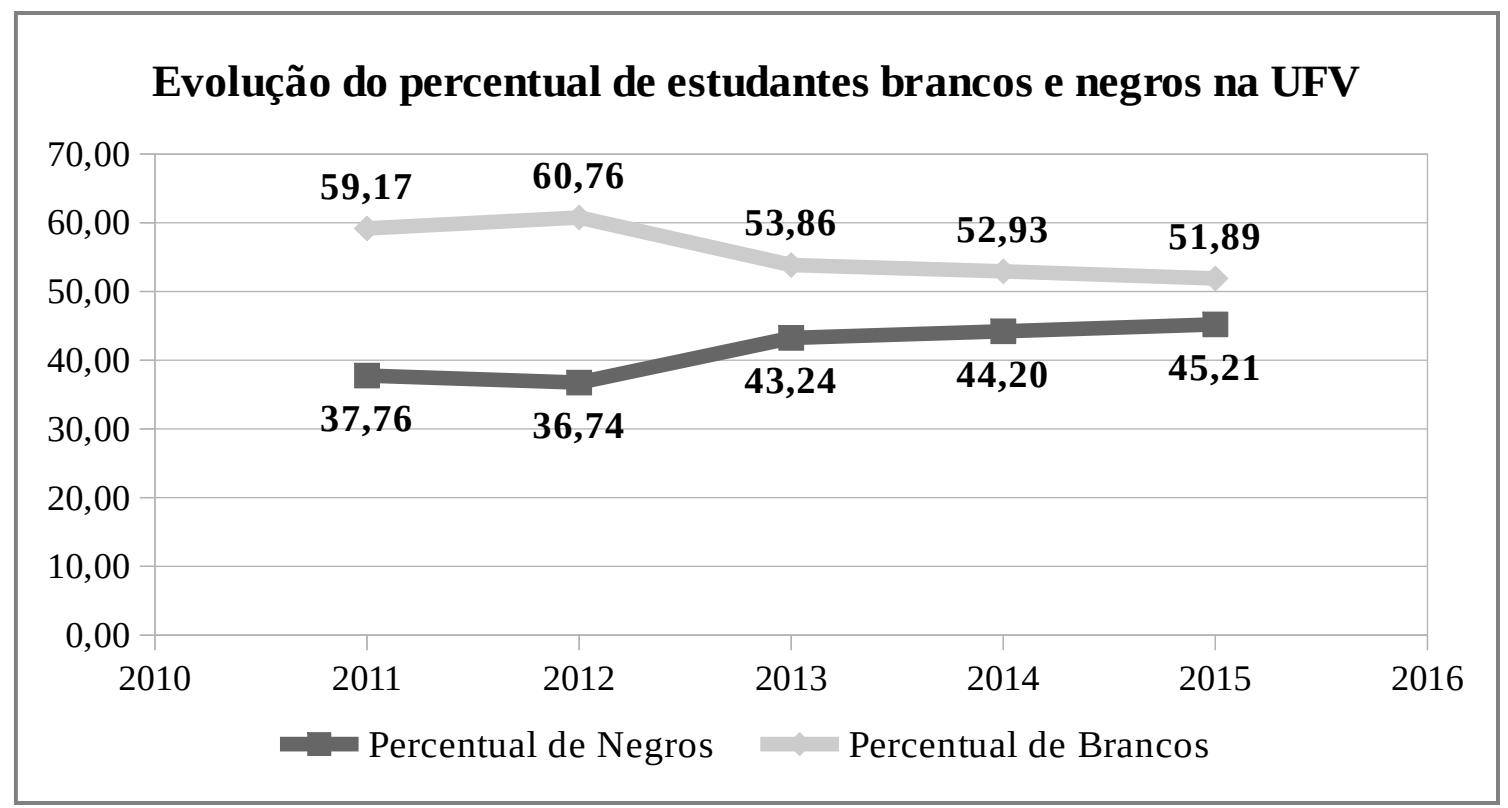

Gráfico 4: Evolução do percentual de estudantes brancos e negros na Universidade Federal de Viçosa entre os anos de 2011 e 2015. Fonte: Registro de dados da RES. Elaborado pela autora.

Destaca-se, no entanto, que nossa noção de pertencimento perpassa a noção de características fenotípicas (traços característicos dos negros), identidade (de aceitar-se como parte desse grupo), mas também diz respeito às relações que este grupo (negros) possui com o espaço (Universidade Federal de Viçosa).

Neste sentido, Halbwachs (1990: 133) relata que cada lugar ocupado por determinados grupos recebe sua marca, ou seja, o espaço é transformado por estes e, em contrapartida, os grupos se adaptam às condições que não podem modificar. Neste contexto, para investigar a presença negra na Universidade Federal de Viçosa, mais que mensurar quais eram os negros nesta instituição, foi preciso 
saber se estes sujeitos se reconheciam como pertencentes a este grupo social bem como quais as relações dos mesmos com este espaço, uma vez que, de acordo com o autor, os grupos estão conectados a um lugar devido às relações criadas por sua proximidade espacial, ou seja, pelas relações de um membro com o outro, do grupo com o espaço e com outros grupos.

Sublinha-se que há alguns anos, discutir a questão racial no Brasil era uma situação incômoda, muitas vezes, ainda o é, sendo que diversas ações e políticas foram utilizadas no sentido de "apagar" o período escravocrata e a presença negra da história do país. Inúmeros exemplos podem ser citados, desde a política de branqueamento adotada após a abolição até a criação do utópico conceito de democracia racial, resultando no que Burke (2000: 85) classificou como amnésia social ou atos de esquecimento. E estes mecanismos de amnésia social refletem diretamente na memória social do grupo, na seletividade da memória, isto é, naquilo que o grupo escolhe memorizar ou esquecer.

Ademais, até o ano de 2003, a presença negra no Brasil e as contribuições dos negros para a cultura do país eram tratadas nos livros de história simplesmente a partir da perspectiva da escravidão, como se a presença negra no país se limitasse ao período escravocrata, em uma clara tentativa de apagá-los da história do Brasil. Somente com a promulgação da Lei n. ${ }^{0}$ 10.639/2003 é que esta realidade começou a ser modificada com a inclusão de temas como

estudo da História da África e dos Africanos, a luta dos negros no Brasil, a cultura negra brasileira e o negro na formação da sociedade nacional, resgatando a contribuição do povo negro nas áreas social, econômica e política pertinentes à História do Brasil. (BRASIL, Lei n. ${ }^{\circ}$ 10.639, 2003: art. 26A)

Entretanto, apesar de tal processo de mudança, tendo em vista que cada vez mais instituições e programas de pós-graduação têm se dedicado a pesquisas a respeito da temática racial, muitas vezes, devido a estes "atos de esquecimento", durante a pesquisa de campo nos deparamos com situações que dificultaram o andamento da mesma, tais como, pessoas negras que não se sentiam como ou que ficaram incomodadas em discutir sobre a questão racial e inclusive pessoas pertencentes a outros grupos que se sentiram da mesma forma. Ou seja, na busca pelos espaços apropriados por este grupo dentro da UFV, na procura destas memórias silenciadas, algumas vezes, encontramos indivíduos que se sentiam pertencentes a este grupo e integrados à instituição, mas também aqueles que se sentiam excluídos tanto de um quanto do outro, pois assim como

\footnotetext{
a cidade é o lugar que produz a diferença, estimula a diversidade, expõe o contraste, o pertencimento, a exclusão, a identidade e a alteridade. A cidade expõe ainda a produção do novo, fabrica o que se chama de a novidade, seja no domínio das mercadorias e objetos, seja no dos valores, ideias, éthos, mas também no elenco de personagens, tipos de conflitos, práticas sociais, relações entre os grupos. (PESAVENTO, 2012: 397)
}

Isso também acontece com a diversidade de grupos e a complexidade de relações constituídas dentro da UFV, bem como, nas relações desta com a cidade de Viçosa/MG, pois, como bem observa E20:

A universidade não é um universo a parte da sociedade, então, aqui a gente também tem uma representação do que a gente tem fora daqui, em termos sociais, assim. 'Cế' passa das 4 pilastras, 'cê' vai fazer uma radiografia quem é que varre as ruas, quem é lixeiro, quem 'tá' nos serviços essenciais e você pega os cargos de administração da prefeitura ou as lojas. Quem são os empresários, quem são os maçons, quem são essa gente? 'Num' são pessoas negras, assim. Então, isso é muito claro. E às vezes as pessoas 'fala' "ah, mas tem Fulano. 'Tá' que ótimo que 'cê' consegue enxergar uma pessoa”, mas isso 'num' é um, sabe, 'num'é uma realidade isso aí. Até em número de professores, mesmo, eu fico pensando assim, a gente tem pouquíssimos professores 
negros, assim. É, talvez hoje a gente tenha um pouco mais de alunos e alunas, mas professores e professoras, não, sabe? Talvez essas políticas que a gente tem visto transformem, um pouco essa realidade, assim. (E20, masculino, cargo: auxiliar em administração)

Cabe salientar que as quatro pilastras que delimitam o espaço do campus universitário e da cidade (BAÊTA, 2016: 168), de modo simbólico, têm funcionado como uma barreira invisível. Com efeito, a análise dos dados de naturalidade dos pesquisados revelou que entre estudantes e servidores técnico-administrativos/docentes apenas $21,15 \%$ e $29,83 \%$, respectivamente, eram de naturalidade viçosense, o que corrobora esse entendimento da existência, ainda que inconscientemente, dessa barreira social. Enquanto que entre os autodeclarados negros, $24,50 \%$ dos estudantes e $34,06 \%$ dos servidores eram naturais de Viçosa/MG.

Destaca-se que para diagnosticar e analisar a presença negra na UFV, mais do que quantificar, diz respeito a recuperar as marcas deste grupo nos vários espaços da instituição, como salas, laboratórios, estátuas, quadros e demais instrumentos, a fim de valorizar a memória destes. Isto é, identificar os traços daquilo que é constituinte da identidade social e responsável por acionar a lembrança de "algo importante" ao grupo. A este respeito, Burke (2000: 74-75) afirma que as imagens tangíveis, como fotografias e monumentos, são constituídas com o objetivo de auxiliar na conservação e na propagação das memórias.

Portanto, considerando a Universidade Federal de Viçosa enquanto espaço social, buscou-se levantar a relação de marcas simbólicas e/ou iconográficas do negro na UFV, sejam enquanto nomes de edifícios, medalhas de mérito, manifestações culturais, dentre outros. Neste sentido, foram identificados 07 (sete) marcas, a saber: o Prédio Francisco São José e a medalha José Valentino da Cruz, assim nomeados em homenagem aos servidores negros de mesmos nomes; o grupo de maracatu "O Bloco" que objetiva o estudo dos ritmos de percussão afrobrasileiros; a "Capoeira Alternativa", atualmente projeto de extensão da instituição; o Núcleo de Estudos Afro-brasileiros (NEAB Viçosa); o Centro de Referência e Pesquisa da Cultura Afro-brasileira e a Casa de Candomblé e Umbanda Ilê Aiyê de Oxóssi. Ressalta-se que também consideramos as 254 ações extensionistas e os 40 projetos de pesquisas relacionados à temática racial, desenvolvidos na UFV, como uma manifestação da presença negra na instituição, posto que, além de representatividade, garantem visibilidade a este grupo.

Sublinha-se que tambem buscamos saber quantas destas marcas eram efetivamente simbólicas para este grupo, isto é, saber se os membros do grupo se identificavam com estes objetos/monumentos e (re)conheciam os processos sociais dos quais estes eram resultantes. Entretanto, percebeu-se que a maioria dos vestígios encontrados não eram simbólicos para os entrevistados, uma vez que dos 25 servidores participantes das entrevistas, apenas 05 (cinco) revelaram conhecimento de duas dessas marcas, sendo citados o NEAB e/ou a história do servidor José Valentino da Cruz, conforme aponta as falas de E02, E09, E20 e E22. Os demais não conheciam estes objetos/monumentos e sequer os processos sociais dos quais estes foram resultantes.

Eu acho que é bem tímido. Eu conheço outros setores que mexem com política pública e com... Aqui na instituição tem o... NEAB da UFV eu acho muito tímido e voltado muito pra cultura. Tem outros NEAB's Brasil a fora que tem o cunho bem mais informativo e político, entendeu? Eu cito da onde eu formei, da UFES, que o NEAB dá capacitação pra pessoas do município, hoje banca uma pós lato sensu com recorte racial. Então o NEAB da UFV, na minha opinião, tá muito tímido ainda. (Eo2, masculino, cargo: arquivista) 


\begin{abstract}
Destacou na UFV? É pessoa que se destacou na UFV? Pode ser pessoas, qualquer pessoa que já passou pela UFV? Servidor que já passou pela UFV? O Candinho, o pai da servidora nossa [D. Maria José da Cruz], ele fez um trabalho... Ele foi o responsável pelo sopão da UFV, ele teve uma contribuição, tem uma... Tem o nome lá de uma rua com o nome dele... Ele foi uma pessoa que contribuiu muito. (Eo9, masculino, cargo: assistente em administração)

Talvez, assim, institucional, eu num conheço. É, eu conheço iniciativas de movimentos, óbvio, a universidade de alguma maneira, apoia, mas é não conheço nenhuma iniciativa oficial ou a gente não tem nenhum monumento exaltando. Cê num tem, cê num tem, sei lá, a universidade, de alguma maneira, abarca isso apoiando os movimentos, mas quem capitania isso são os movimentos, mesmo, sociais, assim. O...Esqueço sempre o nome dos meninos lá... O NEAB e, basicamente, o NEAB também, num sei se tem outras [...] (E2O, masculino, cargo: auxiliar em administração)

Não conheço. Num sei. Eu acho que o NEAB foi a melhor coisa que aconteceu nos últimos anos, mas eu não consigo pensar fora, muito, do trabalho que faz o NEAB. Não sei se a gente tem outros espaços, outras coisas, eu num sei. (E22, feminino, cargo: docente)
\end{abstract}

Em vista disso, é importante a construção de espaços para exposição e valorização dos atos importantes dos grupos, ou seja, criar lugares de memória que, segundo Nora (1981: 13), são lugares que "nascem e vivem do sentimento que não há memória espontânea, que é preciso criar arquivos (...) porque essas operações não são naturais".

Ainda segundo Nora (1981: 21), estes são locais revestidos de materialidade, funcionalidade e simbolismo, ou seja, é um espaço que possui uma aura mística/sentimental, uma utilidade e uma concretude para determinado(s) grupo(s). Nesta mesma perspectiva, Halbwachs (1990: 143) ressalta a importância do espaço para manutenção e propagação de memórias e da conservação neste das marcas do que se pretende lembrar.

No caso específico de Viçosa, em 2009, foi proposta a criação do Centro de Referência da Cultura Afro-brasileira da Zona da Mata Mineira Norte, mais tarde renomeado para Centro de Referência e Pesquisa da Cultura Afro-brasileira através do Programa de Extensão Universitária (PROEXT). Localizado na UFV e alocado na Casa 14 da Vila Antônio Secundino de São José (Vila Secundino), o Centro de Referência tinha como objetivo agrupar em um único espaço os projetos de extensão referentes à questão racial, bem como, arquivar a "memória social" da cultura afro-brasileira.

Contudo, desde sua criação, o Centro de Referência e Pesquisa da Cultura Afro-brasileira não cumpriu com seu principal objetivo, tendo se tornado tão somente um espaço de religiosidade vinculado à Casa de Candomblé e Umbanda Ilê Ayê. Cabe ressaltar que se a proposta inicial do Centro de Referência tivesse sido mantida, este decerto seria um lugar de memória, no qual expor as marcas da presença negra encontradas durante a pesquisa e a história dessas. Por fim, salientamos que nenhum dos entrevistados, quando indagados sobre o conhecimento de algum espaço/momento de valorização do negro na instituição, sabiam da existência de um Centro de Referência na UFV.

\title{
Considerações finais
}

Os resultados encontrados demonstram que, no tocante ao quadro funcional, aparentemente, a Universidade Federal de Viçosa ainda é composta por uma maioria de servidores brancos, sendo que essa "supremacia" branca é apenas provável, posto que a instituição não possui os dados de autodeclaração racial de todos os seus servidores ativos. 
Já em relação aos estudantes, apesar da ausência de informações nos anos anteriores a 2011, os dados apresentados demonstram que a UFV caminha para uma equidade racial na ocupação das vagas de graduação, resta saber se esta igualdade é a mesma para todos os cursos.

Portanto, percebe-se que, com a adoção das políticas raciais inclusivas, diversas representações vêm sendo construídas ao longo do tempo, algumas positivas e outras negativas, a exemplo do aumento crescente no número de negros pertencentes ao quadro funcional e estudantil da UFV e dos parcos vestígios simbólicos e/ou iconográficos de tal grupo encontrados na instituição.

Entrentato, as discussões a respeito da temática racial que se prolongam por muitos anos, tornando-se estratégias de revindicações por parte do movimento negro, necessitam de definições claras e de políticas públicas voltadas de fato para a valorização social desta população nos seus vários espaços. É importante ressaltar que isso vem sendo realizado, consistentemente ou não, nos diversos programas governamentais, ou seja, estão sendo realizadas algumas tentativas que a longo prazo saberemos sua efetividade.

Quanto aos vestígios da presensa negra na UFV, destacamos que apesar de termos encontrado algumas marcas deste grupo na instituição, poucos servidores as conheciam. Salientamos ainda que na instituição não existem espaços específicos destinados à exposição e valorização de tais marcas, sendo que o Centro de Referência da Cultura Afro-brasileira, que viria a ser um espaço importante para a exibição destes feitos, infelizmente, teve sua finalidade modificada. Logo, concluimos que, se nenhuma ação for tomada, a histórias desses objetos e atores permanecerão desconhecidas, salvo por trabalhos ocasionais, a exemplo deste.

Por fim, sublinhamos que estes dados revelam que os espaços negros na UFV ainda são restritos e/ou invisibilizados. Contudo, as marcas encontradas evidenciam que, a despeito da limitada visibilidade conquistada, os estudantes e servidores negros, que passaram e ainda passam pela instituição, escreveram e continuam a escrever seus nomes na história da UFV, sendo necessário trazer ao conhecimento tais relatos.

Recebido em 13 de abril de 2018.

Aprovado em 25 de janeiro de 2019.

\section{Referências}

BAÊTA, Odemir Vieira. Estratégias como práticas sóciodiscursivas em uma Universidade Pública: uma abordagem crítica. 2016.439 f. Tese (Doutorado em Administração) - Universidade Federal de Lavras, Lavras, 2016.

BARRETO, Eloah Monteiro Andrade. Povo de santo: umbandistas de Viçosa. 2010. 81 f. Trabalho de Conclusão de Curso (Bacharel em Comunicação Social/Jornalismo) - Universidade Federal de Viçosa, Viçosa, 2010. 
BRAGA, Tuwile Jorge Kin. A territorialidade do servidor negro da Universidade Federal de Viçosa. 2014. 78 f. Trabalho de Conclusão de Curso (Bacharel em Geografia). Universidade Federal de Viçosa, Viçosa, 2014.

BRASIL. Constituição da República Federativa do Brasil de 1988. Promulgada em 5 de outubro de 1988. Disponível em: <http://www.planalto.gov.br/ccivil_03/constituicao/constituicaocompilado.htm>. Acesso em: 13 set. 2018.

BRASIL. Constituição dos Estados Unidos do Brasil, de 18 de setembro de 1946. Disponível em: <http://www.planalto.gov.br/ccivil_03/Constituicao/Constituicao46.htm>. Acesso em: 13 set. 2018.

Decreto n. ${ }^{\circ} 4.228$, de 13 de maio de 2002. Institui, no âmbito da Administração Pública Federal, o Programa Nacional de Ações Afirmativas e dá outras providências. Disponível em: <http://www.planalto.gov.br/ccivil_03/decreto/2002/D4228.htm>. Acesso em: 13 set. 2018.

Lei ${ }^{\circ}{ }^{\circ} 1.390$, de o3 de julho de 1951 . Inclui entre as contravenções penais a prática de atos resultantes de preconceitos de raça ou de cor. Disponível em: <http://www.planalto.gov.br/ccivil_03/LEIS/L139o.htm>. Acesso em: 13 set. 2018.

Lei n. ${ }^{\circ} 7.716$, de o5 de janeiro de 1989. Define os crimes resultantes de preconceito de raça ou de cor. Disponível em: <http://www.planalto.gov.br/ccivil_03/LEIS/L7716.htm>. Acesso em: 13 set. 2018.

Lei . $^{\circ} 10.639$, de o9 de janeiro de 2003. Altera a Lei n. ${ }^{0} 9.394$, de 20 de dezembro de 1996, que estabelece as diretrizes e bases da educação nacional, para incluir no currículo oficial da Rede de Ensino a obrigatoriedade da temática "História e Cultura Afro-Brasileira", e dá outras providências. Disponível em: <http://www.planalto.gov.br/ccivil_03/leis/2003/l10.639.htm>. Acesso em: 13 mai. 2015.

. Lei ${ }^{\circ}{ }^{\circ} 12.288$, de 20 de julho de 2010. Institui o Estatuto da Igualdade Racial; altera as Leis $\mathrm{n}^{\mathrm{OS}} 7.716$, de 5 de janeiro de 1989, 9.029, de 13 de abril de 1995, 7.347, de 24 de julho de 1985, e 10.778, de 24 de novembro de 2003. Disponível em: <http://www.planalto.gov.br/ccivil_03/_Ato20072010/2010/Lei/L12288.htm> . Acesso em: 04 abr. 2016.

. Lei . $^{\circ} 12.711$, de 29 de agosto de 2012. Dispõe sobre o ingresso nas universidades federais e nas instituições federais de ensino técnico de nível médio e dá outras providências. Disponível em: <http://www.planalto.gov.br/ccivil_03/_ato2011-2014/2012/lei/l12711.htm>. Acesso em: 13 mai. 2015 .

. Lei.$^{\circ} 12.990$, de o9 de junho de 2014. Dispõe sobre a reserva aos negros 20\% (vinte por cento) das vagas oferecidas nos concursos públicos para provimento de cargos efetivos e empregos públicos no âmbito da administração pública federal, das autarquias, das fundações públicas, das empresas públicas e das sociedades de economia mista controladas pela União. Disponível em: <http://www.planalto.gov.br/ccivil_03/_Ato20112014/2014/Lei/L12990.htm>. Acesso em: 15 jun. 2015.

BURKE, Peter. Variedades de história cultural. Tradução de Alda Porto. Rio de Janeiro: Civilização Brasileira, 2000. 
CASA AFRO-RELIGIOSA Ilê Aiyê de Oxossi: Viçosa - MG [Página na internet]. Disponível em: <http://umbandavicosa.blogspot.com/>. Acesso em: 13 nov. 2016.

CASA DE REFERÊNCIA à Cultura Afro Brasileira [Página na internet]. Disponível em: <http://casa-afro.blogspot.com/>. Acesso em: 26 abr. 2017.

COELHO, Elaine. Projetos e Programas aprovados no Edital no o6/20o9 do PROEXT. Disponível em: <https://www2.dti.ufv.br/ccs_noticias/scripts/exibeNoticia.php?codNot $=9645>$. Acesso em: 02 mai. 2017.

COSTA, Fernando Antônio Alves da. Riqueza e escravidão em uma localidade da Zona da Mata Mineira - Santa Rita do Turvo 1850/59. Revista de História Econômica \& Economia Regional Aplicada, v. 8, n. ${ }^{\circ}$ 15, p. 30-50. Juiz de Fora: jul/dez. 2013. Disponível em: <http://www.ufjf.br/heera/files/2009/11/Artigopara-Heera-_Rev.-da-UFJF_-IIpara-pdf.pdf>. Acesso em: 15 nov. 2015.

FERREIRA, Maria Cecília de Moura; SANTOS, Maria Helena Gomes dos. Programa Brasil, Gênero e Raça: Superando a discriminação no trabalho. In: INSTITUTO de Pesquisa Econômica Aplicada. IPEA. Boletim de Mercado de Trabalho - Conjuntura e Análise, n.o 13. Brasília: IPEA, Junho 2000. Disponível em: <http://www.ipea.gov.br/portal/images/stories/PDFs/mercadodetrabalho/mt_o13f.pdf>.Acesso em: 29 set. 2016.

FIALHO, Edson Soares [Gestor]. Centro de Referência da Cultura Afro-Brasileira da Zona Norte: Cultura Negra e Memória Social [Cópia do Projeto disponibilizada pelo gestor]. p. 01-17.

GODOY, Arnaldo Sampaio de Moraes. O tema das quotas para afrodescendentes em concursos públicos. Revista da AJURIS - Associação dos Juízes do Rio Grande do Sul, v. 40, n. ${ }^{\circ}$ 132, Dezembro 2013.

GONZAGA, Yone Maria. Trabalhadores e trabalhadoras técnico-administrativo em educação na UFMG: Relações raciais e a invisibilidade ativamente produzida. 2011. 233 f. Dissertação (Mestrado em Educação) - Universidade Federal de Minas Gerais, Belo Horizonte, 2011. Disponível em: <http://www.bibliotecadigital.ufmg.br/dspace/handle/1843/BUOS-8RWRAU>. Acesso em: 26 set. 2015.

HALBWACHS, Maurice. A memória coletiva. São Paulo: Vértice, 1990.

HARKOT-DE-LA-TAILLE, Elizabeth; SANTOS, Adriano Rodrigues dos. Sobre escravos e escravizados: percursos discursivos da conquista da liberdade. In: SIMPÓSIO NACIONAL DISCURSO, IDENTIDADE E SOCIEDADE, 3., 2012, Campinas. Anais eletrônicos. Campinas: UNICAMP, 2012. Disponível em: <https://www.iel.unicamp.br/sidis/anais/pdf/HARKOT_DE_LA_TAI-

LLE_ELIZABETH.pdf>. Acesso em: 26 set. 2018.

HERINGER, Rosana. Ação afirmativa, estratégias pós-Durban. Observatório da Cidadania, p. 55-61, 2002. Disponível em: <http://www.socialwatch.org/sites/default/files/pdf/en/panorbrasileirob2002_bra.pdf $>$. Acesso em: 30 set. 2016.

HONÓRIO, Letícia de Melo. A produção do espaço em uma cidade universitária: o caso de Viçosa, MG. 2012. 119 f. Dissertação (Mestrado em Geografia) Universidade Federal de Minas Gerais, Departamento de Geografia, 2012. Disponível em: <http://www.bibliotecadigital.ufmg.br/dspace/handle/1843/MPBB8XSMZP>. Acesso em: 14 mai. 2016. 
INSTITUTO Brasileiro de Geografia. IBGE. Características étnico-raciais da população: um estudo das categorias de classificação de cor ou raça 2008. Rio de Janeiro: IBGE, 2011. Disponível em: <https://biblioteca.ibge.gov.br/visualizacao/livros/liv49891.pdf>. Acesso em: 14 abr. 2016.

. Censo Demográfico 2010. Características da população e dos domicílios: resultados do universo. Brasil: IBGE, 2010. Disponível em: <http://www.ibge.gov.br/home/estatistica/populacao/censo2010/caracteristicas_da_populacao/caracteristicas_da_populacao_tab_brasil_zip_xls.shtm >. Acesso em: 16 nov. 2015 .

. Censo Demográfico 2010. Características da população e dos domicílios: resultados do universo. Minas Gerais: IBGE, 2010. Disponível em: <http://www.ibge.gov.br/home/estatistica/populacao/censo2010/caracteristicas_da_populacao/caracteristicas_da_populacao_tab_munici-

pios_zip_xls.shtm>.Acesso em: 16 nov. 2015 .

JACCOUD, Luciana. (Org.). A construção de uma política de promoção da igualdade racial: uma análise dos últimos 20 anos. Brasília: IPEA, 2009. Disponível em: <http://www.ipea.gov.br/portal/images/stories/PDFs/livros/livro_aconstrucao_igualdade_racial2oanos.pdf>. Acesso em: 19 jul. 2016.

LIMA, Edilson Vitorelli Diniz. O equívoco brasileiro: cotas raciais em concursos públicos. RDA - Revista de Direito Administrativo, Rio de Janeiro, v. 271, p. 281315, jan./abr. 2016.

MATTOS, Hebe Maria. Escravidão e Cidadania no Brasil Monárquico. 2 ed. Rio de Janeiro: Jorge Zahar, 2004.

NEAB VIÇOSA - Núcleo de Estudos Afro-brasileiros [Página na internet]. Disponível em: <http://neabvicosa.blogspot.com.br/p/historico-do-neab-ufv.html>. Acesso em: 30 out. 2016.

NORA, Pierre. Entre memória e história: a problemática dos lugares. São Paulo: Revista Projeto História, 1981, p. 7-28.

O BLOCO [Página na internet]. Disponível em: <http://oblocovicosa.blogspot.com.br/p/sobre-o-bloco.html > . Acesso em: 22 out. 2016.

OSORIO, Rafael Guerreiro. “A classificação de cor ou raça do IBGE revisitada”. In: PETRUCCELLI, José Luis; SABOIA, Ana Lucia. (Org.). Características étnico-raciais da população: classificações e identidade. Estudos e análises - Informação demográfica e socioeconômicas, Rio de Janeiro: IBGE, 2013. Disponível em: <https://biblioteca.ibge.gov.br/visualizacao/livros/liv63405.pdf >. Acesso em: 21 out. 2016.

. O sistema classificatório de "cor ou raça" do IBGE. Texto para

discussão n. ${ }^{\circ}$ 996. Brasília: IPEA, nov. 2003. Disponível em: <http://www.ipea.gov.br/portal/images/stories/PDFs/TDs/td_0996.pdf>.

Acesso em: 31 out. 2018.

PESAVENTO, Sandra Jatahy. História, literatura e cidades: diferentes narrativas para o campo do patrimônio. Revista do Patrimônio Histórico e Artístico Nacional, n. ${ }^{\circ} 34,2012$.

PRAXEDES, Vanda Lúcia; TEIXEIRA, Inês Assunção de Castro; SOUZA, Anderson Xavier de; GONZAGA, Yone Maria. (Org.). Memórias e percursos de professores negros e negras na UFMG. Belo Horizonte: Autêntica, 2009. 
PRÉDIO DA IMPRENSA Universitária já tem nome de Francisco São José. UFV Informa, Viçosa, ano 16, n. ${ }^{\circ}$ 851, 12 de julho de 1984.

QUEIROZ, Delcele M. Quem são os negros? Classificação racial no Brasil: aproximação e divergências. Trabalho apresentado na $25^{\mathrm{a}}$ Reunião Anual da Associação Nacional de Pós-Graduação e Pesquisa em Educação, Caxambu, 29 set./2 out. 2002. Caderno de resumos. Disponível em: <http://www.anped.org.br/sites/default/files/gto3_05.pdf >. Acesso em: 30 out. 2018.

REZENDE, Vanessa Elkhoury. Ação afirmativa e concurso público: reserva de cotas para os afro-brasileiros. Site Funcional do Procurador de Justiça Aroldo José de Lima. Artigos. p. 1-20. Campo Grande, [entre 1998 e 2007]. Disponível em: <http://www.projustica.com.br/viewcontent.php?m=mainlist\&cod=114> . Acesso em: 29 ago. 2016.

SANTOS, Sales Augusto dos. "Ação afirmativa e mérito individual”. In: SANTOS, Renato Emerson dos; LOBATO, Fátima. (Org.). Ações Afirmativas: políticas públicas contra as desigualdades raciais. Rio de Janeiro: DP\&A, 2003.

SILVA, Tatiana Dias; SILVA, Josenilton Marques da. Reserva de vagas para negros em concursos públicos: uma análise a partir do Projeto de Lei 6.738/2013. Nota Técnica n. ${ }^{0}$ 17. Brasília: IPEA, 2014. Disponível em: $<$ http://www.ipea.gov.br/portal/images/stories/PDFs/nota_tecnica/140211_notatecnicadisoc17.pdf.pdf >. Acesso em: 28 jul. 2016.

SOUSA, Tommy. Programa de Extensão Capoeira Alternativa oferece aulas de capoeira infantil. Disponível em <https://www2.dti.ufv.br/ccs_noticias/scripts/exibeNoticia2.php? codNot=24071>. Acesso em: 07 nov. 2016.

TEIXEIRA, Moema De Poli. Negros na universidade: identidade e trajetórias de ascensão social no Rio de Janeiro. Rio de Janeiro: Pallas, 2003.

UNIVERSIDADE Federal de Viçosa. UFV. Conselho Universitário. CONSU. Resolução n. ${ }^{\circ}$ og de 26 de julho de 1996. Cria a Medalha José Valentino da Cruz (Candinho) e aprova seu Regimento.

Secundino. p. 01-53.

. Processo . $^{\circ}$ Oo $7570 / 2009$ - Solicita liberação da casa 14 da Vila

. Registro de Atividades de Extensão. RAEX. Disponível em: <https://www2.dti.ufv.br/raex/scripts/dadosAtividade.php>. Acesso em: 26 abr. 2017.

. Sistema de Pesquisa e Pós-Graduação. SisPPG. Disponível em: <https://www2.dti.ufv.br/sisppg/scripts/portal/>. Acesso em: 26 abr. 2017.

VALVERDE, Orlando. Estudo regional da Zona da Mata de Minas Gerais. Revista Brasileira de Geografia, $\mathrm{n}^{0}$ 1, p. 3-79. Rio de Janeiro: 1958. Disponível em: $<$ http://biblioteca.ibge.gov.br/visualizacao/periodicos/115/rbg_1958_v20_n1.pdf >. Acesso em: 15 abr. 2016. 